\title{
A RESSIGNIFICAÇÃO DA DEMOCRACIA DIANTE DA(S) CRISE(S) DO ESTADO: UM NOVO CAMINHO FRENTE A RACIONALIDADE NEOLIBERAL
}

\section{Amanda Netto Brum ${ }^{1}$}

\section{Resumo}

O presente estudo tem como tema central a ressignificação da democracia frente à(s) crise(s) do Estado no contexto da racionalidade neoliberal. Assim, por meio da técnica de pesquisa da documentação indireta da pesquisa bibliográfica, inicialmente, apresenta-se o Estado diante das crises de seus fundamentos. Posteriormente, realiza-se uma reflexão acerca do processo e das consequências que a "fórmula da homogeneidade" proporciona aos sujeitos e ao próprio Estado. Finalmente, expõe-se a necessidade de (re)pensar a concepção da democracia atual frente à racionalidade neoliberal e, desse modo, propõe-se ressignificá-la por meio do aparato participativo da Fraser (2009), pois entende-se que tal construção teórica pode ser uma ferramenta potente - ao dar respostas aos novos questionamentos que se opõem no cenário atual - para reativar concepções emancipatórias e de empoderamento frente às novas subjetividades decorrentes da lógica neoliberal.

Palavras-chave: Estado. Crises do Estado. Racionalidade neoliberal. Democracia.

\section{INTRODUÇÃO}

Muitos têm sido os debates acerca da instituição Estado ${ }^{2}$ nos dias atuais. No entanto, há ainda diversos questionamentos possíveis, especialmente acerca das crises dos fundamentos dessa que é a maior instituição político-jurídica da modernidade. Neste contexto, diversas problematizações acerca da concepção da democracia

\footnotetext{
${ }^{1}$ Doutoranda em Direito Público - Unisinos. Mestre em Direito e Justiça Social - FURG. E-mail: amandanettobrum@gmail.com ${ }^{2}$ Ost (1999) adverte que "de todas as instituições suscetíveis de obrigar o futuro, a mais importante foi, e ainda é em larga medida, o Estado, na condição de poder contínuo.
} 
têm sido levantadas. De fato, são muitas as abordagens e teorias que buscam significar a democracia atualmente.

Frente a isso, a concepção da democracia como valor de civilização e não de Estado figura no pensamento contemporâneo ${ }^{3}$ e é de fundamental importância na configuração de um novo conjunto teórico para que se possa pensar em uma forma político-jurídica diante da racionalidade ${ }^{4}$ neoliberal. Demonstra-se, frente este contexto, fundamental problematizar a concepção da democracia, pois esta não pode estar a serviço do estadocapitalista-mercadológico.

Isso porque a partir do pensamento de Dardot e de Laval (2016), a razão do capitalismo contemporâneo, isto é, o neoliberalismo, antes de ser uma ideologia ou uma política econômica é, em primeiro lugar e fundamentalmente, uma racionalidade e como tal tenta estruturar e organizar não apenas a ação dos governantes, mas as próprias dos governados. Dessa forma, a instituição político-jurídica central da modernidade o Estado - vem passando por uma mutação e este processo subverte radicalmente os fundamentos modernos da democracia.

Propõe-se, então, (re)pensar a democracia a partir da análise das crises pelas quais o Estado enfrenta, particularmente a crise política, pois o modelo de democracia liberal representativa apresenta-se insuficiente frente às novas demandas sociais - aliás, tal crise está na base da origem do Estado -; como será demonstrado no primeiro momento deste estudo.

Já em um segundo momento, será evidenciado que a essência dos sujeitos e do próprio Estado - diante do contexto neoliberal - está associada a um certo grau de homogeneidade social, ou seja, determinados sujeitos não passam no controle de qualidade rigoroso da política neoliberal, assim, aqueles que não atingem bom desempenho no campo concorrencial, bem como grupos em vulnerabilidade, como negros, imigrantes, homossexuais são compreendidos como peças defeituosas e, como tal, não integram as esferas públicas e são, portanto, impedidos de uma participação efetiva - como pares nas interações sociais - dos espaços públicos.

Diante desse contexto, será proposto ressignificar a concepção da democracia por meio do aparato participativo de Fraser (2009b), pois entende-se que tal construção pode ser uma ferramenta potente para pensar os novos questionamentos que surgem a partir das novas subjetividades criadas pela plasticidade dos sujeitos diante da razão neoliberal.

Cabe pontuar, por fim, que a técnica de pesquisa da documentação indireta utilizada será a da pesquisa bibliográfica. Assim, será realizada uma revisão bibliográfica ancorada fundamentalmente nos referencias teóricos de Bolzan de Morais (2011), Fraser (2003, 2009a, 2009b) e Dardot e Laval (2016).

\footnotetext{
${ }^{3}$ Utiliza-se tal expressão, neste escrito, para significar dias atuais.

${ }^{4}$ Neste estudo a racionalidade neoliberal será estruturada a partir da formulação e compreensão de Dardot e de Laval (2016) na sua obra "A nova razão do mundo - ensaio sobre a sociedade neoliberal".
} 


\section{O ESTADO DIANTE DAS CRISES DE SEUS FUNDAMENTOS}

Diversas são as maneiras por meio das quais as crises ${ }^{5}$ do Estado ${ }^{6}$ são abordadas teoricamente, no entanto, neste escrito, tal temática será estruturada a partir do marco teórico proposto por Bolzan de Morais (2011). Cabe estabelecer, inicialmente, que ao ser proposto o estudo das crises dos fundamentos do Estado não se está propondo a análise da extinção dessa forma político-jurídica constituída na modernidade, mas, sim, buscase analisar o conjunto de fenômenos que englobam as alterações e transformações que ocorrem desde o seu surgimento (BOLZAN DE MORAIS, 2011).

Produto da modernidade, o Estado é "um fenômeno original e histórico de dominação" (BOLZAN DE MORIAIS, STRECK, 2013, p. 29). No entanto, tal forma jurídico-política tem sofrido profundas transformações, particularmente nas últimas décadas - provenientes das alterações nas ordenações paradigmáticas que os estruturam. E, é diante deste cenário que o estudo das crises de seus fundamentos apresenta-se de fundamental importância para que se possa compreender seus limites, suas possiblidades e suas interconexões, especialmente com a concepção da democracia.

Importa, neste momento, tecer algumas ponderações acerca das crises que afetam a instituição Estado. Torna-se fundamental, primeiramente, compreender que "mesmo apresentadas separadamente, as crises, compõem um mosaico único" (BOLZAN DE MORAIS, 201 1, p.25), e, por isso, devem ser compreendidas por meio das suas interconexões.

Assim, cabe trazer observações das crises em cinco perspectivas. Dessa forma, de acordo com a denominação proposta por Bolzan de Morais (2011), serão analisadas as seguintes vertentes: a conceitual, a estrutural, a constitucional (institucional), a funcional e, fundamentalmente, para o objeto desta pesquisa, a política (e da representação).

Nessa perspectiva, a primeira vertente das crises a ser analisada, a conceitual, interroga a mais cara característica do Estado, isto é, o seu "poder como soberania" (BOLZAN DE MORAIS, 2011, p. 25). A soberania

\footnotetext{
${ }^{5}$ Conforme Cassese (2010) a crise do Estado é teorizada desde o início do século XX e, primeiramente, propôs-se esta com o surgimento de organismos potentes, como sindicatos e grupos industriais que questionaram a soberania interna do Estado. Já em seguida, a crise do Estado foi utilizada para indicar a criação de poderes públicos internacionais que acabam concorrendo com o poder estatal. Ainda, em um mais recente significado, esta se refere à inadequação dos serviços estatais em relação às expectativas dos cidadãos e da sociedade em geral. E, também, a expressão é utilizada para indicar a diminuição das atividades estatais, por meio de privatizações e concessões da entidade do Estado a sujeitos privados. Já para Pasold et al (2016, p. 16) o "Estado está em crise porque suas versões reformadas são incapazes de responder, satisfatoriamente, às solicitações da Sociedade”.

${ }^{6}$ Quando se fala em Estado, neste estudo, está-se fazendo referência à experiência moderna, pois a partir da compreensão de Bolzan de Morais e de Streck (2013) as experiências anteriores a essa estruturação devem ser pensadas como pré-modernas e, portanto, não há que se confundir com a instituição Estado.

${ }^{7}$ Para Chaui (2006, p. 39) a ideia de que o Estado representa toda a sociedade e de que todos os cidadãos estão representados nele é uma das grandes forças para legitimar sua característica de dominação.
} 
entendida como o poder estatal incontestável, uno, imprescritível e inalienável dentro dos limites territoriais do Estado-nação ganha novos contornos diante do alargamento dos limites territoriais possibilitados pela globalização ${ }^{8}$. Dito de outra forma, o fenômeno da globalização possibilita a "desterritorialização" da manifestação do poder e do direito ${ }^{10}$.

Há de se ter em mente que, embora se entenda que a globalização tenha desencadeado um esvaziamento progressivo nas funções essenciais do Estado, isso não significa que um mundo sem soberania tenha se tornado possível. Para Chevallier (2009, p. 15), “a perspectiva de um 'mundo' sem soberania configura-se no atual estágio um verdadeiro mito, desprovido de uma dimensão real ${ }^{11}$.

Aliás, desde Jean Bodin o conceito de soberania implica necessariamente - para os Estados-Nação perder um pouco deste poder, "era esta precisamente a tradicional casus belli"(CASTELLS, 2010, p. 354). De lá para cá, inúmeras foram as mutações por que passaram os Estados Nacionais fato que, consequentemente, implicou transformações no conteúdo deste poder.

Diante disso, para Bolzan de Morais ${ }^{12}$ a crise conceitual ${ }^{13}$ relativiza a soberania como

poder que é juridicamente incontrastável, pelo qual se tem a capacidade de definir e decidir acerca do conteúdo e da aplicação das normas, impondo-as coercitivamente dentro de um determinado espaço geográfico, bem como fazer frente a eventuais injunções externas (BOLZAN DE MORAIS, 2011, p. 27)

aponta para a necessidade de se repensar tal conceituação frente às novas realidades que se impõem. De acordo

\footnotetext{
${ }^{8}$ De acordo com Beck (1999, p. 47) "globalização significa a experiência cotidiana da ação sem fronteiras nas dimensões da economia, da informática, da ecologia, da técnica dos conflitos transculturais e da sociedade civil [...] que transforma o cotidiano com uma violência inegável e obriga todos a se acomodarem a sua presença e a fornecer respostas". Ou apenas, segundo Bauman a partir de Jowitt, a globalização é a nova "deseordem" mundial (1999).

${ }^{9}$ Cabe pontuar que tal terminologia não significa o fim da ideia de território (limites físicos), mas evidencia que a globalização modifica tais limites, transformando-os em elementos secundários (MENEZES NETO, 2016).

${ }^{10}$ Castells (2010, p. 358) ao pontuar que para Giddens (1985), o Estado-nação é um repositório de poder, o principal da era moderna, traz um importante questionamento acerca da forma que devemos conceitualizar esta instituição, num momento em que as fronteiras estão desaparecendo e os próprios repositórios de poder estão sendo envolvidos em outras forças. Para o autor, a interrogação que se impõe é: "para efeito de continuidade teórica, o Estado-nação está sendo superado pelas transformações que se apresentam?" (CASTELLS, 2010, p. 358).

${ }^{11}$ Parece, no entanto, que Pasold et al (2016) estrutura seu pensamento em sentido distinto, pois, ao pontuar acerca da possibilidade de futuro para "entidade Estado" estabelece que "os novos Estados exerceriam sua atividade não como entidades soberanas, mas como parte componente de uma ordem política internacional mais ampla e complexa. Assim, o Estado tende a extinguir-se como estrutura soberana e como coordenador de uma hierarquia piramidal. $O$ novo 'Estado' não seria mais pretenso gestor de uma hierarquia soberana, mas sim um potencial negociador e integrador de sua comunidade no contexto internacional" (PASOLD et al., 2016, p.16).

${ }^{12}$ Bolzan de Morais (2011) ao estruturar o estudo da crise conceitual opta em realizá-lo a partir dos acontecimentos mais recentes da flexibilização deste poder, no entanto, o autor não desconsidera o percurso histórico da soberania e sua influência na compreensão atual do poder soberano.

${ }^{13}$ A crise conceitual do Estado também afeta os outros elementos característicos do Estado, isto é, povo e território, pois "a soberania ao ser caracterizada por uma estrutura de poder centralizado e que exerce o monopólio da força política - legislativa, executiva e jurisdicional - sobre um determinado território - como um espaço geográfico delimitado por fronteiras - e a população - com um conjunto de indivíduos que é reconhecido como cidadão/nacional - que o habita" (BOLZAN DE MORAIS, 2011, p.27).
} 
com o autor, percebe-se que tanto no nível das relações externas quanto no âmbito do próprio Estado - a partir, fundamentalmente, da emergência e consolidação das novas relações sociais -, um esfacelamento/esboroamento da soberania estatal, expondo, assim, os desafios, em tempos de globalização, da teoria e da prática do Estado.

Frente à contínua transformação ${ }^{14}$ imposta e operada pela incorporação da questão social diante dos Estados Nacionais é que o Estado Social ${ }^{15}$ é forjado. E é diante deste "novo arranjo" estatal que a crise estrutural passa a ser problematizada. O Estado do Bem-Estar Social

é pois como Estado protetor que o Estado moderno se identifica. No século XX, em compensação, as missões do Estado alargaram-se, na medida em que ele toma a seu cargo, para além da simples sobrevivência, a garantia de uma certa qualidade de vida. Preocupado com a realização efetiva das promessas de liberdade e de igualdade para todos, o Estado social pretende dominar os principais riscos sociais, impondo a segurança generalizada. Nunca a solidariedade voluntarista terá sido levada tão longe, nunca a confiança no futuro um futuro balizado pela ciência, obrigado pela lei e garantido por um contrato de seguro mútuo - terá sido tão forte (OST, 1999, p. 337).

Dessa forma, o projeto do Estado Social ${ }^{16}$ sofreu e sofre por sua incapacidade em consolidar o projeto antropológico ${ }^{17}$ que não apenas the compõe sentido como também the materializa (BOLZAN DE MORAIS, 2011). Há um enfraquecimento das estruturas públicas frente aos direitos sociais, isto é, o Estado Social demostrase incapaz de concretizar suas promessas.

A crise aqui é estruturada porque o Estado ao invés de excluir tem como pressuposto a inclusão. Ocorre que, no contexto da globalização, as estruturas que possibilitam este modelo estatal estão sujeitas a diversos tensionamentos.

\footnotetext{
${ }^{14}$ Ao pontuar as crises que a instituição enfrenta "modelos" de Estado são elencados. No entanto, torna-se fundamental advertir que, muito embora, para efeitos didáticos - e até mesmo funcional - a abordagem realizada a partir da construção dialética de que "o Estado Liberal é apresentado como a tese, o Estado Social a antítese e o Estado democrático de Direito a síntese", retrate a sucessão cronológica, esta, no entanto, não enfrenta as características fundamentais que definem cada formato estatal, e, sendo assim, não define de forma ordenada a evolução dos modelos estatais (MARDEN, 2016, p. 197).

15 "O que irá diferenciar substancialmente o modelo do Estado interventivo contemporâneo à forma de Estado do Bem-Estar dos Estados assistenciais anteriores é o fato de a regulação não significar a troca das garantias pela liberdade pessoal, uma vez que o beneficiado, no último caso, era considerado perigoso à ordem pública e, na perspectiva da caritas protestante, eram vistos como não iluminados pelas bênçãos divinas, ao passo que, no modelo de Bem-Estar, as prestações públicas são percebidas e construídas como um/uma direito/conquista da cidadania. Além disso, há uma diferença substancial entre as políticas de bem-estar propostas num quadro de assistencialismo daquelas de um modelo democrático que tem em seu interior o compromisso com concretização de sua função social" (BOLZAN DE MORAIS, STRECK, 2013, p.49).

${ }^{16}$ Ainda, representa efetivamente uma transformação superestrutural por que passou o antigo Estado liberal. Seus matizes são riquíssimos e diversos. Mas algo, no ocidente, o distingue, desde as bases, do Estado proletário, que o socialismo marxista tenta implantar: é que ele conserva sua adesão à ordem capitalista, princípio cardeal a que não renuncia (BONAVIDES, 2011, p. 185).

${ }^{17} \mathrm{~A}$ base antropológica, de acordo com Bolzan de Morais $(2011$, p. 48) "pretende dispor de agentes dotados de uma compreensão coletiva, compartilhada e compromissada de ser-estar do mundo. Todavia, o que se observou foi, muitas vezes, apenas a transformação do indivíduo liberal em cliente da administração, apropriando privadamente a poupança pública ou adotando estratégias assistencialistas de distribuição das respostas estatais e dos serviços públicos, quando não, naqueles locais onde a fórmula do Bem-Estar Social apenas como farsa foi forjada, elaborando-se mecanismos de constituição do consenso social desde um processo de infantilização dos atores, para além do assistencialismo que lhe suporta".
} 
Inseridos nestes encontram-se - conjuntamente ${ }^{18}$ com a dificuldade de angariar recursos públicos suficientes para assegurar os direitos sociais dos indivíduos, crise fiscal-financeira - a) o embate entre a burocratização do acesso ao espaço público e o aumento da demanda, o que materializa, segundo Bolzan de Morais (2011), a crise ideológica; e b) a crise filosófica, esta que é estruturada no fundamento da solidariedade e "atinge os fundamentos sobre os quais se assenta este modelo estatal" (BOLZAN DE MORAIS, 201 1, p. 48).

A partir da transformação paradigmática na qual o Direito passa a ser transformador frente às fórmulas ordenadora (Estado Liberal de Direito) e promovedora (Estado Social de Direito) um novo modelo de Direito e de Estado é construído (STRECK, 2014) ${ }^{19}$. O Estado democrático de direito destina-se, então, segundo Streck (2014, p. 333), "justamente para instrumentalizar o direito -, como um campo privilegiado na concretização dos direitos sociais". Já, em termos conceituais, o que o Estado Democrático de Direito tem de "democrático" é o fato de que se trata de um modelo estatal submetido a um direito construído democraticamente (MADEN, 2016).

E, é frente a este novo paradigma, que a terceira crise do Estado é refletida. A crise constitucional (institucional) projeta-se, portanto, sobre a fórmula moderna de racionalização do poder, ou seja, do Estado Constitucional. Dito de outra maneira, a crise constitucional é visualizada "como um processo de desconstituição promovida pelo 'dito neoliberalismo"” (BOLZAN DE MORAIS, 2011, p.51).

Streck (2014), ao definir a crise constitucional, também considera o impacto do neoliberalismo. Para o autor, para além dos fatores endógenos que influenciam a crise constitucional há, ainda, os fatores exógenos, esses que, segundo Streck (2014), são reflexos do neoliberalismo e, ao impactarem o Direito, acabam delimitando o texto constitucional e a sua condição de aplicação.

Nesse contexto, apresenta-se fundamental questionar a estrutura do Estado democrático de direito. E é a partir da interrogação quanto ao funcionamento dessas estruturas que a crise funcional é pensada por Bolzan de Morais. A denominada crise funcional - decorrência direta da crise conceitual -, segundo o autor, é materializada a partir "da multiplicidade do loci de poder, gerando a perda de centralidade e exclusividade do Estado" (BOLZAN DE MORAIS, 2011, p. 56). Isto é, há o enfraquecimento do Estado como fonte única do poder frente à concorrência - interna e externa - com outros poderes que são contextualizados na contemporaneidade.

\footnotetext{
${ }^{18}$ De acordo com Bolzan de Morais (201, p. 43) a crise fiscal-financeira do Estado parece materializar as demais - ou, pelo menos, da maioria -, as críticas que se fazem ao Estado Social e das propostas de sua revisão tendentes a um retorno atrás, na perspectiva da flexibilização/fragilização das estruturas de política públicas de caráter social, sobretudo, e de algumas que sustentam a necessidade de um rearranjo sustentável das estruturas sociais ante seus pressupostos econômicos.

${ }^{19}$ Streck (2009) esclarece que "o século XX foi generoso para com o Direito e a filosofia. No Direito, o segundo pós-guerra proporcionou a incorporação dos direitos de terceira dimensão ao rol dos direitos individuais (primeira dimensão) e sociais (segunda dimensão). Às facetas ordenadora (Estado Liberal de Direito) e promovedora (Estado Social de Direito), o Estado Democrático de Direito agrega um plus (normativo): o Direito passa a ser transformador, uma vez que os textos constitucionais passam a conter as possibilidades de resgate das promessas da modernidade” - situação que, de acordo com Streck (2009), "assume relevância ímpar em países de modernidade tardia como o Brasil, em que o welfare state não passou de um simulacro".
} 
Nesse sentido, apresenta-se interessante a forma com que Bauman estabelece seu posicionamento acerca deste questionamento, segundo o autor,

ninguém parece estar no controle agora. Pior ainda - não está claro o que seria, nas circunstâncias atuais "ter controle". Como antes, todas as iniciativas e ações de ordenações são locais e orientadas para questões específicas; mas não há mais localidade com arrogância bastante para falar em nome da humanidade como um todo ou para ser ouvida e obedecida pela humanidade ao se pronunciar. Nem há uma questão única que possa captar e teleguiar a totalidade dos assuntos mundiais e impor a concordância global (BAUMAN, 1999, p. 66).

Dessa forma, para além do viés interno (dialética da separação/harmonização das funções estatais), apresenta-se necessário problematizar o externo, pois a transnacionalização promovida pela globalização alterou profundamente a ideia de espaço-tempo, fazendo com que haja um esvaziamento e uma fragilização do modelo clássico estatal.

A última vertente das crises a ser analisada é a que Bolzan de Morais (2011) denominou de crise política e da representação. Cabe mencionar que, frente à análise que se propõe realizar neste escrito, o entendimento deste viés da crise apresenta-se de fundamental importância, pois é a partir deste que será problematizada a concepção da democracia. Assim, a crise política e da representação caracteriza-se pelo esvaziamento da política, especialmente em razão do seu distanciamento com os problemas sociais (BOLZAN DE MORAIS, 2011).

Segundo Bolzan de Morais, há uma "fantochização" da democracia, pois a democracia contemporaneamente tornou-se:

um instrumento incapaz de responder adequadamente a todos os anseios, pretensões, intenções etc., o que conduz a tentativas de esvaziá-la como lugar adequado ao jogo da política de "fantochizá-la" - tornando-a apenas um estereótipo formal pela ausência de alternativas reais de escolha (BOLZAN DE MORAIS, 2011, p. 70).

Há, portanto, uma fragilização/esfacelamento da democracia $^{20}$ frente à insuficiência do sistema político estruturado a partir do viés da representação.

O modelo de democracia liberal representacional apresenta-se um mecanismo incapaz de responder adequadamente aos anseios, pretensões e intenções frente às novas subjetividades estabelecidas pela racionalidade neoliberal (DARDOT, LAVAL, 2015). O fato fundamental é, segundo Dardot e Laval (2016, p. 384), que "o neoliberalismo tornou-se hoje a racionalidade dominante, não deixando da democracia liberal nada além de um envelope vazio, condenada a sobreviver na forma degradada de uma retórica ora comemorativa, ora marcial".

Cabe, no entanto, mencionar que, inicialmente, o capitalismo reforçou a lógica democrática nas sociedades contemporâneas, contudo, foi a partir das medidas de austeridade ${ }^{21}$ propostas pelos governos na década de 1970 que os Estados - ao cederem o controle do mercado ao "turbo-capitalismo" - perderam força

\footnotetext{
${ }^{20}$ A relação entre Estado e democracia é fulcral, ao menos em relação ao Estado democrático de direito, já que sem aquele esse resta descaracterizado (MARDEN, 2016).
} 
diante do poderio do mercado e, a partir disso, a concepção de democracia passou a ruir (LIPOVETSKY, 2004).

Com isso, o Estado que, até então, pretendia-se como mecanismo "emancipador" - ao deixar esfacelar a instância democrática diante do mercado - passa a compor mais um braço da estruturação capitalista (LIPOVETSKY, 2004). Diante desse contexto, torna-se necessário avançar para uma nova significação da democracia; que possa transpor o princípio do mercado.

Assim, frente à razão neoliberal, há de se "reconhecer que o sistema político calcado na ideia de representação política padece, como as demais estratégias erigidas pela modernidade ocidental" (BOLZAN DE MORAIS, p. 73, 2011). Demonstra-se, portanto, primordial questionar esta concepção de democracia, pois talvez, a partir deste questionamento, possa-se pensar um novo projeto democrático que - ao ultrapassar as insuficiências do modelo atual - reative concepções emancipatórias e de empoderamento em nosso contexto social (FRASER, 2009a) frente às novas subjetividades decorrentes da lógica neoliberal.

\section{AS NOVAS SUBJETIVIDADES DIANTE DA RACIONALIDADE NEOLIBERAL}

Na realidade contemporânea, as mudanças e o desenvolvimento na maneira de relacionar-se e viver dos indivíduos, grupos e classes vêm alterando e determinando novos anseios, desejos e interesses que interrogam os limites e as possibilidades das instituições e sistemas modernos, propiciando situações de precariedade e exclusão aos sujeitos plurais de direito. Frente a essa realidade, torna-se fundamental ampliar os olhares e ressignificar conceitos para que novos métodos e abordagens possam ser repensados no desafio de transpor a razão neoliberal.

Já que segundo Dardot e Laval com o neoliberalismo

o que está em jogo é nada mais nada menos que a forma de nossa existência, isto é, a forma como somos levados a nos comportar, a nos relacionar com os outros e com nós mesmos. $\mathrm{O}$ neoliberalismo define certa norma de vida nas sociedades ocidentais e, para além dela, em todas as sociedades que as seguem no caminho da modernidade (DARDOT, LAVAL, 2016, p. 16).

Santos (2005) ao estabelecer que o neoliberalismo "é assente no primado das leis do mercado, uma vez que todo o instrumentário conceptual, tanto ideológico como técnico, da governança vai contra aquele que subjaz à lógica do mercado", aparenta usar a mesma linha teórica que Dardot e Laval (2016) para estruturar sua construção do pensamento acerca desta estrutura.

Os autores concordam que se apresenta fundamental transpor a lógica neoliberal na ordem social contemporânea, pois tal estrutura impõe a reconfiguração dos sistemas e instituições da modernidade,

\footnotetext{
${ }^{21} \mathrm{O}$ modelo implicou abolição dos investimentos estatais na produção, abolição do controle estatal sobre o fluxo financeiro, drástica legislação antigreve e vasto programa de privatização (CHAUÍ, 2006, p. 313).
} 
particularmente da instituição Estado. Isso porque "a governança ${ }^{22}$ neoliberal entrelaça cada vez mais três dimensões do poder: a condição das empresas, a condução dos Estados, e por fim, a condução do mundo" (DARDOT, LAVAL, 2016, p. 276).

Santos (2010), no entanto, diferentemente da proposta de Dardot e Laval (2016), estrutura seu pensamento a partir do embate entre os paradigmas dominante versus dominado. $\mathrm{O}$ autor parece não considerar o neoliberalismo como uma racionalidade e, talvez, por isso, desconsidere que "as respostas" a esta razão não podem ser estruturadas apenas a partir da "dimensão negativa".

Isto é, para $\operatorname{Santos}^{23}$ (2010) o pensamento abissal moderno regula as relações entre os sujeitos e entre estes e o Estado. Frente a isso, apresenta-se necessário estabelecer uma resistência política fundada na resistência epistemológica e isso só se tornará possível, no pensamento do autor, mediante o desenvolvimento de um pensamento pós-abissal, este que deveria se contrapor ao pensamento abissal e que surgiria no seio de um cosmopolitismo subalterno:

O cosmopolitismo subalterno manifesta-se através das iniciativas e movimentos que constituem a globalização contra-hegemónica. Consiste um vasto conjunto de redes, iniciativas, organizações e movimentos que lutam contra a exclusão económica, social, política e cultural gerada pela mais recente encarnação do capitalismo global, conhecido como globalização neoliberal (Santos, 2010, p. 51).

Santos (2010) é preciso no diagnóstico, entretanto, sua abordagem não é capaz de dar resposta à lógica neoliberal como uma racionalidade, pois "o neoliberalismo não destrói apenas regras, instituições, direitos. Ele também produz certos tipos de relações sociais, certas maneiras de viver, certas subjetividades" (DARDOT, LAVAL, 2016, p. 16). Desse modo, fica evidente que Santos (2010) desconsidera a real abrangência da razão neoliberal, pois - este ao também construir e não apenas destruir - constrói novas subjetividades, novos anseios, quereres e desejos no contexto social e, consequentemente, modifica, substancialmente, um dos principais fundamentos do Estado, ou seja, a democracia.

Para que se possa ampliar as discussões quanto ao neoliberalismo e seus impactos frente à instituição Estado torna-se fundamental compreendê-lo a partir de uma racionalidade e não apenas como uma doutrina econômica ou ideológica. Isso porque tal razão vem transformando profundamente as estruturas sociais e

\footnotetext{
${ }^{22}$ A governança neoliberal é visualizada por Dardot e Laval (2016, p.276) como um fator que enfraquece a soberania dos Estados no contexto atual. Pois, "a governança, neste sentido, pressupõe obediência às injunções dos organismos que representam os grandes interesses comerciais e financeiros. Um Estado, a partir da governança neoliberal, não deve mais ser julgado por sua capacidade de assegurar soberania sobre territórios, mas pelo respeito que demonstra às normas jurídicas e às boas práticas econômicas da governançă".

${ }^{23}$ Santos (2010), no primeiro capitulo da obra "Epistemologia do Sul" intitulado "Para além do pensamento abissal: linhas globais a uma ecologia de saberes" enfatiza que o pensamento moderno ocidental é um pensamento abissal e, diante disso, torna-se fundamental combater tal cenário e, para tanto, o autor propõe um esforço coletivo no desenvolvimento de uma epistemologia do sul, dentro do qual haveria um movimento principal e um contramovimento subalterno. $\mathrm{O}$ autor estrutura seu pensamento, novamente, a partir do embate entre a linha de cá (Sul) e a linha de lá (Norte).
} 
instituições modernas de forma subterrânea e difusa, "estendendo seu sistema normativo a todas as relações sociais, sem deixar incólume nenhuma esfera da existência humana” (DARDOT, LAVAL, 2016, p.15).

Apresenta-se, diante desse cenário, fundamental pensar de que maneira uma resposta - que transponha o embate entre os paradigmas da apropriação/violência e da regulação/emancipação - pode ser estruturada, pois o indivíduo exigido pelo modelo capitalista neoliberal é um sujeito formado e consumido por este modo de produção e consumidor do resultado da sua produção, logo, alijado dos espaços de convívio democrático (SPENGLER, 2008).

Frente a isso - e reconhecendo que a racionalidade neoliberal forma uma nova lógica normativa nas sociedades ocidentais -, apresenta-se fundamental analisar, diante das lentes foucaultianas ${ }^{24}$, como o discurso estabelecido pela razão neoliberal forma e constrói o sujeito. Cabe, inicialmente, estabelecer que, segundo Foucault ${ }^{25}$, o discurso nada mais é do que a reverberação de uma verdade (FOUCAULT, 1999), e que a produção de discursos aceitos como verdadeiros é marcada pela obediência da política discursiva, isto é, na sociedade contemporânea, da racionalidade neoliberal.

O que quer dizer que

estamos submetidos à produção da verdade também no sentido em que ela é lei e produz o discurso verdadeiro que decide, transmite e reproduz, ao menos em parte, efeitos de poder. Afinal, somos julgados, condenados, classificados, obrigados a desempenhar tarefas e destinos a um certo modo de viver ou morrer em função dos discursos verdadeiros que trazem consigo efeitos específicos de poder (FOUCAULT, 2014, p. 279).

Cabe pontuar que, por verdade, Foucault (2014, p. 53) "não quer se referir ao conjunto de coisas verdadeiras a descobrir ou a fazer aceitar", mas refere-se "ao conjunto das regras segundo as quais se distingue o verdadeiro do falso e se atribui ao verdadeiro efeitos específicos de poder". "A verdade não existe fora ou sem o poder", assim, a verdade está de acordo com o pensamento foucaultiano, "circularmente ligada a sistemas de poder, que a produz e apoia, e a efeito de poder que ela induz e que a reproduz" (FOUCAULT, 2014, p. 54).

Desse modo, segundo o autor, "cada sociedade tem seu regime de verdade, sua 'política geral' de verdade", ou seja, "os tipos de discursos que ela acolhe e faz funcionar como verdadeiros" (FOUCAULT, 2014, 52). É diante disso que cada sociedade estabelece "as técnicas e os procedimentos que são valorizados para a obtenção da verdade; o estatuto daqueles que têm o encargo de dizer o que funciona como verdadeiro é

\footnotetext{
${ }^{24}$ Frydman (2016) em sua obra "O fim do Estado de Direito - governar por standards e indicadores", ao também utilizar a concepção foucaultiana, pontua acerca do outro lado da história das normas. Assim, o autor traz que o pensamento de Foucault continua moderno e que, mesmo que o teórico não tenha se debruçado acerca do impacto das normas técnicas, sua teorização, acerca das normas de gestão, pode ser utilizada para pensar o impacto daquelas normas no contexto social. Dessa forma, segundo o autor, Foucault traz as normas, também, como um mecanismo de poder e, como tal, é compreendido, diante da teoria foucaultiana, como um mecanismo que disciplina e administra a população.

${ }^{25}$ Para Foucault (2014) o sujeito é efeito do discurso.
} 
produzido por múltiplas coerções" (FOUCAULT, 2014, p. 52) cada sociedade tem, portanto, "sua 'política geral' de verdade" (FOUCAULT, 2014, p. 52).

É preciso, dessa forma, alterar o regime político, econômico, institucional de produção de verdade, pois este "regime de verdades não é simplesmente ideológico ou superestrutural; foi e ainda é uma condição de formação e desenvolvimento do capitalismo" (FOUCAULT, 2014, p. 54) - isto é, da razão neoliberal - que marca o próprio desenvolvimento da ordem social contemporânea. O ponto crucial é, pois, desvincular o poder da verdade das formas de hegemonias, particularmente as políticas, sociais e as culturais (FOUCAULT, 2014), a partir das quais são estruturadas as regulamentações e articuladas as normatizações da atual ordem discursiva, ou seja, da racionalidade neoliberal.

Seguindo o pensamento foucaultiano, o poder não somente forma o sujeito, mas, fundamentalmente, torna-o possível. O sujeito, então, forma-se dentro da lógica neoliberal, isto é, diante de um conjunto de práticas formadoras que caracterizam novos modos de subjetividades, pois

essa racionalidade tomou corpo num conjunto de dispositivos discursivo, institucionais, políticos, jurídicos e econômicos que formam uma rede complexa e movediça [...]. Podemos falar, nesse sentido, de um dispositivo global que, que como qualquer dispositivo é de natureza essencialmente estratégica (DARDOT, LAVAL, 2016, p. 384).

Fica claro, portanto, a partir do proposto por Dardot e Laval (2016), que os sujeitos também estão diante da governamentalidade empresarial. E é por meio desta forma de governamentalidade que novas aspirações e novas condutas são descritas, e, fundamentalmente, novos modos de controle e influência são exercidos sobre o comportamento dos sujeitos, isto é:

do sujeito ao Estado, passando pela empresa, um mesmo discurso permite articular uma definição do homem pela maneira como ele quer ser "bem-sucedido, assim como pelo modo como dever ser "guiado", "estimulado", "formado", "empoderado" (empowered) para cumprir seus objetivos, que e são impostos pela racionalidade neoliberal (DARDOT, LAVAL, 2016, p. 332).

Assim, diante do contexto da mercantilização neoliberal, o funcionamento heterogêneo dos sujeitos é substituído pela homogeneidade do discurso do homem em torno da figura da empresa (DARDOT, LAVAL, 2015). Dessa forma, "essa nova figura do sujeito (homogenizado) opera uma unificação sem precedentes das formas plurais da subjetividade que a democracia liberal permitiu que se conservassem e das quais sabia aproveitar-se para perpetuar sua existência" (DARDOT, LAVAL, 2016, p. 326).

A partir de então, segundo os autores, há a fabricação do "sujeito empresarial" ou "neossujeito". A grande inovação tecnológica, segundo Dardot e Laval (2016), do neoliberalismo é, justamente, conectar a maneira como o sujeito é governado à maneira como ele próprio se governa.

Ao retomar o pensamento foucaultiano, no entanto, entende-se que, em última instância, a governamentalidade é o movimento pelo qual os sujeitos são assujeitados a uma prática social mediante 
mecanismos de poder. Desse modo, compreendendo que o poder funciona como mecanismo estruturante da racionalidade neoliberal -, para além dos limites da governamentalidade empresarial não se "é", em outros termos, habita-se um domínio de uma ontologia precária ${ }^{26}$.

Assim, mesmo que se compreenda que o neossujeito é "reflexo do tempo atual" utiliza-se, entretanto, de uma justificativa falaciosa ao usar a concepção emancipatória do neossujeito - pois a ética empresarial ao encerrar as formas éticas, exaltando "o homem que faz a si mesmo" e "a plena realização" (DARDOT, LAVAL, 2016) busca, na verdade, singularizar os sujeitos no contexto social.

A governamentalidade empresarial pode aparentar ser uma experiência criativa e emancipatória aos indivíduos - ao produzir sujeitos empreendedores, mas, efetivamente não o é, pois reforça as relações de competição entre estes e exige que eles se adaptem subjetivamente às condições cada vez mais duras e competitivas que eles mesmos produziram.

Trata-se, sim, de uma tendência que busca a homogeneização dos sujeitos e, em última instância, do próprio Estado. Daí decorre que aqueles que não atingem bons desempenhos no campo concorrencial são precarizados e, portanto, alijados dos espaços de convívio democrático.

Aliado a tal pensamento e usando o exemplo proposto por Pasold et al (2016, p. 17), "negros, imigrantes, homossexuais", dentre tantos outros sujeitos que não estão em conformidade com o controle rigoroso de qualidade imposto pela racionalidade neoliberal, também são descartados como "peças com defeito de fabricação". Estas peças "defeituosas" são o resultado da política capitalista, que quer impor um padrão de homogeneidade artificial, insensível e desumana (PASOLD et al, 2016). Tal política impossibilita que esses sujeitos, assim como aqueles que não alcançam o padrão de produção capitalista, integrem as esferas públicas sendo, portanto, impedidos de uma participação efetiva - como pares nas interações sociais - nos espaços públicos.

Há de se ter em mente que a essência da democracia está aliada ao papel do Estado e que este, assim como os sujeitos, ao ser submetido à "governamentalidade empresarial", está condicionado a práticas de homogeneização. As estruturas da instituição Estado, diante deste contexto, cada vez menos oferecem respostas às demandas sociais. De fato, há um esvaziamento de direitos e cidadania - aos sujeitos - diante da racionalidade neoliberal.

Daí a necessidade de refletir acerca da ressignificação da concepção de democracia, pois faz-se, portanto, necessário, frente a esta razão, pensar uma concepção de democracia que transcenda a lógica do capital e que possa ser pensada como uma estrutura a serviço dos seres humanos (OST, 1999).

\footnotetext{
${ }^{26}$ Convém lembrar que para Foucault (2014) onde há poder, há resistência. Dessa forma, como as categorias dos sujeitos precarizados são formadas diante do discurso neoliberal - obviamente que este campo, também, será marcado, no contexto contemporâneo, por atos de resistência.
} 


\section{UM NOVO CAMINHO: A RESSIGNIFICAÇÃO DA DEMOCRACIA}

Tomando, incialmente, a concepção da necessidade da reconstrução de uma abordagem da democracia frente à crise política de representação promovida pela racionalidade neoliberal, faz-se urgente compreendê-la e ressignificá-la para além do modelo estabelecido na atual ordem social. Isso porque as transformações que a instituição Estado sofre são indissociáveis de uma redefinição do liame político, ou seja, da relação entre os sujeitos e entre estes e o Estado (CHEVALLIER, 2009).

Assim, é necessário recordar que

a democracia baseia-se no pluralismo de opinião e nas oposições conflituais. A democracia é o regime que, pela primeira vez na história, não se propõe a eliminar os conflitos, e sim a torná-los visíveis e esforçando-se para lhe garantir desfecho negocial com a ajuda de procedimentos aceites. Num regime democrático, o conflito é, pois, interminável (em termos de hierarquia quanto à instauração dos bens primeiros ou sobre os próprios fundamentos do regime). O próprio sujeito encontra-se sempre em situação de poder modificar a sua própria ordem de prioridades, demonstrando a possibilidade de requestionar sua participação nas práticas sociais existentes. Por aí se vê que a democracia moderna é essencialmente transgressiva, não possuindo base estável (OST, 1999, p. 333).

É nesse sentido que Bolzan de Morais ${ }^{27}$ (1998, p. 93) estabelece que a "democracia é, antes de tudo, um compromisso com a liberdade" e, complementa:

não é crível, numa democracia, que a perenidade formal das regras (que deverão ser normas) assuma contornos de muro que aprisionam os participantes em limites impeditivos do vislumbre do horizonte, onde o sol se põe de forma enigmática, para um novo amanhecer (BOLZAN DE MORAIS, 1998, p. 93).

Apresenta-se fundamental, então, repensar a concretização de uma ordem democrática que transponha as características presentes no atual cenário - já que dentro do quadro referencial contemporâneo, percebe-se que a democracia restou fragilizada ${ }^{28}$.

Para além disso, há de se ter em mente que a democracia, como projeto político, foi idealizada para uma sociedade muito menos complexa que a de hoje. É preciso reconhecer, como afirma Bolzan de Morais e Brum (2016) ao comentarem acerca dos fundamentos do Estado democrático de direito, que os tempos atuais modernos e líquidos - são outros e que estes tempos fomentam novos arranjos, e complementam:

O dilema que nos afeta diz, então, com o reconhecimento desta nova era - não só de direito, mas também de deveres [...] a compreensão dos seus contornos, a estruturação de instrumentos que lhe sejam adequados, a compatibilização de um projeto de salvaguarda de

\footnotetext{
${ }^{27}$ Ainda, Bolzan de Morais (1998) traz, a partir da leitura de Warat, que a democracia necessita ser sentida não somente como uma invenção constante do novo - ela se reconhece no inesperado que reside nos desequilíbrios demasiadamente sólidos de uma ordem de proibições - mas também, como uma condição de significações que comanda nossos processos de autonomia, abrindoos à imprevisibilidade de suas significações.

${ }^{28}$ Dardot e Laval (2016, p.384) entendem que, enquanto doutrina, o neoliberalismo "é não acidentalmente, mas essencialmente, um antidemocratismo".
} 
conquistas e de construção de novas fórmulas asseguradoras de uma vida digna para humanidade diante de novos dilemas e dos novos dramas, bem lembrando dos déficits que ainda experimenta relativamente às promessas não efetivadas para todos (BOLZAN DE MORAIS, BRUM, 2016, p. 64)

A transformação experimentada frente à racionalidade neoliberal apontou fragilidades de um dos principais fundamentos do Estado, isto é, da concepção atual de democracia e trouxe novas interrogações à política representativa. É preciso, portanto, questionar a atual política representativa (que se encontra em crise) face às contradições de um projeto democrático que se contrapõe à pretensão de certeza e da homogeneidade que configuram e marcam as vivências e experiências dos sujeitos e do próprio Estado.

Ainda, Ost (1999, p. 335) evidencia o risco da "democracia de mercado" e o pensamento único homogeneizante - que a acompanha. Segundo o autor, a problemática consiste, justamente, quando, por detrás dos consensos de fachada, as divergências de interesse são ocultadas e as oposições minimizadas (OST,1999).

Dardot e Laval (2016) advertem, no entanto, que a reposta à racionalidade neoliberal não pode ser buscada em "sistemas decadentes". Esclarecem, nesse sentido, que não se pode propor dar novo fôlego ao sistema democrático liberal, amparando a combatida democracia representativa com as escoras bambas da democracia participativa, já que tal reconfiguração do sistema democrático não responde adequadamente às circunstâncias que decorrem da racionalidade neoliberal.

Contudo, a "(re)democratização" dos espaços públicos apresenta potencialidade para opor a afrontante homogeneização da sociedade contemporânea neoliberal. Nesse sentido, o conceito da paridade participativa (estabelecido por meio da dimensão política) proposto por Fraser (2009b) revela-se potente para pensar os espaços nos quais os sujeitos em um contexto pós-westfaliano são precarizados socialmente, politicamente e juridicamente e pode potencializar estratégias para desconstruir os mecanismos institucionalizados que impedem e inviabilizam a participação efetiva nos espaços públicos.

Isso porque, em termos conceituais, para Fraser, a paridade de participação significa

A distribuição de recursos materiais deve ser de molde a garantir a independência e a "voz" dos participantes. Este chamarei a condição objetiva de paridade participativa. [...] em contraposição, a segunda condição requer que padrões institucionalizados de valor cultural exprimam igual respeito por todos os participantes e garantam a igualdade de oportunidade para alcançar a estima social. Este chamarei a condição intersubjetiva da paridade participativa (FRASER, 2003, p. 36).

E é diante deste contexto que a teoria de Fraser (2009b) demonstra potencialidade frente à racionalidade neoliberal. Fraser estabelece que os conflitos que envolvem as categorias em precariedade devem ser significados como um projeto político mais amplo na ordem social.

A teórica adverte que, diante do contexto da globalização, muitos observam que os "processos" sociais que moldam a vida dos sujeitos rotineiramente transbordam os limites de justiça e, consequentemente, da atual estrutura democrática. Há uma invisibilidade daqueles sujeitos que não se "formam" em conformidade com a 
lógica da governamentalidade empresarial e o resultado é a precarização e exclusão desses dos espaços públicos. Desse modo, a perda de "eficiência" do Estado em oferecer respostas as demandas dos sujeitos - a partir da "fórmula de homogeneização neoliberal" - demonstra a crise do sistema político atual (BOLZAN DE MORAIS, 2011).

É necessário, então, de acordo com Fraser (2009b), combater as injustiças sociais a partir de uma perspectiva "transgressora" que implique a efetivação das dimensões de redistribuição, de reconhecimento e, fundamentalmente, da representação (política) e retome uma normatividade que dirija para a emancipação e ao empoderamento.

Convém ressaltar que o modelo desenvolvido por Fraser (2009a) de correções das injustiças - por meio das dimensões da redistribuição, do reconhecimento ${ }^{29}$ e da representação -, recebeu a nomenclatura "da teoria tridimensional de justiça social”. Fraser (2009a) propõe, em sua teoria, uma alteração paradigmática na forma de compreender os conflitos sociais e políticos, ao estabelecer aquelas três formas de correções dos resultados indesejados provocados pelas injustiças socioeconômica e cultural-valorativa.

Dessa forma, segundo a autora, "somente por meio da integração dos conceitos de reconhecimento, da redistribuição e, especialmente da representação pode-se chegar a um quadro adequado de justiça às demandas do nosso tempo" (FRASER, 2006, p. 246). É possível, então, pensar na fórmula de democracia participativa como uma resposta possível diante da racionalidade neoliberal.

Isso porque para Fraser (2009b) a luta por justiça em um mundo globalizado não pode alcançar êxito se não caminhar juntamente com a luta por democracia. Nesse sentido, cabe ressalvar que o aparato da paridade de participação tem dupla qualidade que expressa o caráter reflexivo da justiça e, sendo assim, da democracia (FRASER, 2009b).

De acordo com a teórica, tal dimensão envolve, então, a noção de resultado que especifica o princípio pelo qual se possibilita avaliar arranjos sociais e, por outro lado, a paridade de participação, envolve a noção de processo, que especifica um padrão procedimental pelo qual se pode avaliar a legitimidade democrática das normas $^{30}$ (FRASER, 2009b).

Em virtude dessa dupla qualidade, a paridade de participação é capaz, segundo Fraser (2009b), de problematizar tanto a substância quanto o procedimento. Tal abordagem pode, dessa forma, corrigir "tanto as injustas decorrentes das situações que distorcem o 'aparente' processo de tomada de decisão, quanto os

\footnotetext{
${ }^{29}$ Cabe evidenciar que, muito embora Fraser (1997) reconheça o questionamento existente em torno da pertinência da distinção entre as categorias das injustiças culturais-valorativas e socioeconômica, por serem entendidas como inseparáveis, a autora utiliza tais categorias distintamente para sua análise, mas adverte que para que se alcance um quadro adequado de justiça faz-se necessária uma abordagem conjunta de tais dimensões.
} 
procedimentos não democráticos que geram resultados substantivamente desiguais" (FRASER, 2009b, p.37). Por isso, a paridade de participação, conforme proposto por Fraser, fornece meios para ressignificar a democracia frente à racionalidade neoliberal.

Portanto, o modelo de democracia participativa estruturada a partir do aparato teórico de Fraser - ao desestabilizar a lógica neoliberal com a inserção dos sujeitos em condições de paridade -, isto é, como parceiros integrais de interação social e política - apresenta-se potente para desvelar respostas diante das novas subjetividades estabelecidas pela racionalidade neoliberal.

\section{CONSIDERAÇÕES FINAIS}

A partir da presente pesquisa, em que foi proposto refletir acerca da necessidade da ressignificação da democracia diante da(s) crise(s) do Estado - especialmente da crise política (de representação) -, no contexto da racionalidade neoliberal, pode-se demonstrar que a teorização proposta por Fraser, com base no aparato da paridade participativa, demonstra-se potente para pensar um projeto político mais amplo e, com isso, ressignificar, a atual concepção da democracia.

Isso porque, as modificações ocasionadas pela racionalidade neoliberal ao "ressituar" a própria estruturação social e, consequentemente, redesenhar novas interrogações ao sistema político calcado na ideia de representação política, demonstraram fragilidades/insuficiências de um dos principais fundamentos do Estado, isto é, da concepção contemporânea da democracia.

Diante deste contexto, convém lembrar que, de acordo com o proposto por Dardot e Laval, a lógica neoliberal, para além de ser um modo de governo que faz da adesão a uma doutrina o meio privilegiado de poder, é, fundamentalmente, uma estrutura que se apoia sobretudo na coerção que exerce sobre os indivíduos a partir das situações de concorrência que coloca em prática por meio da governamentalidade empresarial. O neoliberalismo é, pois, um modo de governo dos sujeitos que afeta todas as instituições modernas, especialmente o Estado.

Assim, sob a ideia da governamentalidade empresarial os sujeitos e o próprio Estado foram inseridos no processo de homogeneização e a consequência disso, como já demonstrado, foi, de um lado, a insuficiência das estruturas estatais frente às demandas sociais e, de outro, a precarização dos sujeitos que não se enquadram nesta fórmula - seja aqueles que não atingem a produção adequada ou os considerados como peças defeituosas pela lógica neoliberal.

Torna-se, neste contexto, fundamental compreender que a essência da democracia está imbricada com a

\footnotetext{
$\overline{{ }^{30} \text { Há de se ter em mente que as normas, a partir da construção foucualtiana, também são mecanismos de poder, como pontuado }}$ acima.
} 
noção de Estado. Ocorre que, diante da racionalidade neoliberal, como pontuado, não apenas os sujeitos, mas o próprio Estado é inserido nas práticas da homogeneização. As estruturas da instituição Estado, diante deste cenário, cada vez menos oferecem respostas às demandas sociais, há, portanto, um esvaziamento de direitos e cidadania - aos sujeitos - frente a lógica neoliberal.

Frente a isso a ressignifição da democracia por meio do aparato participativo da Fraser apresenta-se potente, pois entende-se que tal construção teórica pode ser um aporte importante - ao dar respostas aos novos questionamentos que se apresentam no cenário atual - para reativar concepções emancipatórias e de empoderamento frente às novas subjetividades decorrentes da lógica neoliberal.

Portanto, entende-se que é possível ressignificar a democracia a partir da teorização proposta por Fraser. O modelo de democracia participativa - pensada por meio da construção teórica da autora ao estruturar fórmulas para a inserção dos sujeitos em condições de paridade nos espaços públicos, não somente desestabiliza a lógica da racionalidade neoliberal, como também apresenta potencialidade para desvelar respostas diante das novas subjetividades estabelecidas pela racionalidade neoliberal.

\title{
THE RESIGNIFICATION OF DEMOCRACY FACING THE STATE CRISIS: A NEW WAY TO NEOLIBERAL RATIONALITY IN VIEW OF THE NEOLIBERAL RATIONALITY
}

\begin{abstract}
The central theme of this study is the resignification of democracy in the face of the crisis(es) of the State in the context of neoliberal rationality. Thus, through the technique of indirect documentation research of bibliographic research, first the State is presented, in the face of crises of its fundamentals. Subsequently, it is made a reflection on the process and consequences that the "homogeneity formula" provides to the subjects and the State itself. Finally, it is exposed the need to (re)think the conception of the current democracy against the neoliberal rationality and, therefore, the resignification is proposed through the participatory apparatus of Fraser (2009), since it is understood that such theoretical construction can be a powerful tool - answering the new questions that oppose the current scenario - to reactivate emancipatory conceptions and empowerment in the face of new subjectivities arising from the neoliberal logic.
\end{abstract}

Keywords: State. State Crisis. Neoliberal Rationality. Democracy. 


\section{REFERENCIAS}

ANDRADE, Daniel Pereira. OTA, Nilton Ken. Uma Alternativa ao neoliberalismo. Entrevista com Pierre Dardot e Christian Laval. In: Tempo Social - Revista de Sociologia, 2015. Disponível em: <http://www.scielo.br/scielo.php?script=sci_arttext\&pid=S0103-20702015000100275>. Acessado em: 08 de jul. de 2017.

BAUMAN, Zygmunt. Globalizacão - As consequências humanas. Tradução: PENCHEL, Marcus. Rio de Janeiro: Zahar, 1999

BECK, Ulrich. O que é globalização? Equívocos do globalismo e a resposta à globalização. Tradução: CARONE, Andre. São Paulo: Paz e Terra, 1999.

BOLZAN DE MORAIS, Jose Luis. As crises do estado e da constituição e a Transformação espaço-temporal dos Direitos Humanos. 2 ed rev. ampl. Porto Alegre: Livraria do Advogado Editora, 2011.

A subjetividade do tempo: Uma perspectiva transdisciplinar do direito e da democracia. Porto Alegre: Livraria do Advogado, 1998.

BOLZAN DE MORAIS, Jose Luis, STRECK, Lenio Luiz. Ciência Política e Teoria do Estado. 8 ed. rev. e atual. Porto Alegre: Livraria do Advogado, 2013.

BOLZAN DE MORAIS, Jose Luis, BRUM, Guilherme Valle. Políticas Públicas e Jurisdição Constitucional entre direitos, deveres e desejos. Porto Alegre: Livraria do Advogado Editora, 2016.

BONAVIDES, Paulo. Do Estado liberal ao Estado social. 10 ed. São Paulo: Malheiros Editores, 2011.

CASSESE, Sabino. A crise do Estado. Tradução: MOREIRA, Ilse Paschoal Moreira, ORTALE, Fernanda Landucci. Campinas, SP: Saberes Editora, 2010.

CASTELLS, Manuel. A era da informação: Economia, sociedade e cultura - o poder da identidade. Tradução: GERHARDT, Klauss Brandini. São Paulo: Editora Paz e Terra, 2010. 
CHAUI, Marilena. Cultura e Democracia: o discurso competente e outras falas. 11 ed. rev. ampl. São Paulo: Cortez, 2006.

CHEVALLIER, Jacques. O Estado Pós-moderno. Tradução: JUSTEN FILHO, Maçal. Belo Horizonte: Fórum, 2009.

DARDOT, Pierre, LAVAL, Cristian. A nova razão do mundo: ensaio sobre a política neoliberal. Tradução: ECHALAR, Mariana 1 ed. São Paulo: Boitempo, 2016.

FOUCAULT, Michel. A ordem do discurso. São Paulo: Edições Loyola, 1999.

Microfísica do Poder. 28 ed. Rio de Janeiro: Paz e Terra, 2014.

FRASER, Nancy. O feminismo, o capitalismo e a astúcia da história. In: Dossiê: Contribuições do Pensamento Feminista para as Ciências Sociais. Tradução: Costa Filho, Anselmo da; Cavalcante, Sávio. 2009a.

Reenquadrando a justiça em um mundo globalizado. In: Lua nova. Tradução: FREITAS, Ana Carolina, ASSIS, Mariana. São Paulo, 2009b.

Da redistribuição ao reconhecimento? Dilemas da Justiça na era Pós-socialista. In: SOUZA, Jessé (Org.). Democracia hoje: novos desafios para a teoria democrática contemporânea. Brasília: Editora Universidade de Brasília, 1997.

Justice Social in the Age of Identity Politics. In: FRASER, Nancy; HONNETH, Axel. Redistribution or Recognition?- A Political Philosophical Exchange. London: Verso, 2003.

La jusiticia social em la era de la política de la identidade: redistribuicíon, reconocimiento y participacíon. In: Redistribuicion o Reconocimiento? Um debate político filosófico. Ed. Morata, 2006.

FRYDMAN, Benoit. O fim do Estado de Direito - governar por standards e indicadores. Tradução: KRUG, Maria Beatriz. Porto Alegre: Livraria do Advogado, 2016.

LIPOVETSKY, Gilles. Tempo contra o tempo, ou a sociedade hipermoderna. In: Os tempos hipermodernos, 2004. Disponível em: < Lipovetsky\%20-\%20Os\%20tempos\%20hipermodernos.pdf >. Acesso em 23 de abril de 2017.

MARDEN, Carlos. Democracia sitiada. In: Estado e Constituição. (Org): BOLZAN DE MORAIS, José Luis, 
SARAIVA, Bruno Cozza. 1 ed. Florianópolis, SC: Empório do Direito, 2016.

MENEZES NETO, Elias Jacob. Surveillance, democracia e direitos humanos: os limites do Estado na era da big data. Tese (Doutorado em Direito) - Universidade do Vale do Rio dos Sinos - Unisinos. Programa de PósGraduação em Direito, São Leopoldo, RS, 2016.

OST, FRANÇOIS. O tempo do direito. Tradução: OLIVEIRA, Maria Fernanda. Lisboa: Instituto PIAGET, 1999

PASOLD, Cesar Luis et.al. Reflexões sobre o futuro do Estado Constitucional Moderno. In: Revista Brasileira de Políticas Públicas. (Org.) PASOLD, Cesar Luiz, FERRER, Gabriel Real, CRUZ, Paulo Márcio.V.6 n1. UniCeub, 2016.

SANTOS, Boaventura de Sousa. Para além do pensamento abissal: das linhas globais a uma ecologia dos saberes. In: SANTOS, Boaventura de Sousa, MENESES, Maria Paula. Epistemologia do Sul. São Paulo: Cortez, 2010.

A crítica da governação neoliberal: O Fórum Social Mundial como política e legalidade cosmopolita subalterna. In: Revista Crítica de Ciências Sociais, 2005. Disponível em: <http://www.boaventuradesousasantos.pt/media/pdfs/governacao_neoliberal_RCCS72.PDF >. Acesso em: 01 de jul. de 2017.

SPENGLER, Fabiana Marion. Tempo, Direito e Constituição - Reflexos na prestação jurisdicional do Estado. Porto Alegre: Livraria do Advogado Editora, 2008.

STRECK, Lenio Luiz. Hermenêutica Jurídica e(m) crise - uma exploração hermenêutica da construção do Direito. 1 led. rev. atual e ampl. Porto Alegre: Livraria do Advogado Editora, 2014.

Hermenêutica, Constituição e autonomia do Direito, 2009. In: Revista de Estudos Constitucionais, Hermenêutica e Teoria do Direito (RECHTD). Disponível em: <http://revistas.unisinos.br/index.php/RECHTD/article/view/5137 >. Acesso em: 03 de jul. de 2017.

Trabalho enviado em 05 de março de 2018

Aceito em 10 de junho de 2018 